\title{
The Impact of China's Market Reforms on the Health of Chinese Citizens: Examining Two Puzzles
}

\section{Citation}

Whyte, Martin K and Sun Zhongxin. 2010. The Impact of China's Market Reforms on the Health of Chinese Citizens: Examining Two Puzzles. China: An International Journal, 8:1-32.

\section{Published Version}

http://www.eai.nus.edu.sg/Vol8_No1_Mar2010.pdf

\section{Permanent link}

http://nrs.harvard.edu/urn-3:HUL.InstRepos:12876662

\section{Terms of Use}

This article was downloaded from Harvard University's DASH repository, and is made available under the terms and conditions applicable to Open Access Policy Articles, as set forth at http:// nrs.harvard.edu/urn-3:HUL.InstRepos:dash.current.terms-of-use\#OAP

\section{Share Your Story}

The Harvard community has made this article openly available.

Please share how this access benefits you. Submit a story.

Accessibility 


\title{
THE IMPACT OF CHINA'S MARKET REFORMS ON THE HEALTH OF CHINESE CITIZENS: EXAMINING TWO PUZZLES*
}

\section{Martin King Whyte and Sun Zhongxin}

\begin{abstract}
China's post-1978 market reforms were accompanied by a drastic decline compared to the socialist era in the coverage of the Chinese population by medical insurance as well as by sharp increases in charges for medical treatments, tests, and prescriptions. Since the 1990s these trends have produced widespread condemnation of the current Chinese medical care system as too costly and unequal, a critique embodied in an unprecedented Chinese government report in 2005 that declared the post-1978 reforms of the medical care system a failure. That conclusion helped accelerate efforts to expand health access, health insurance coverage, and government health funding, with the government announcing in 2009 a plan to provide every Chinese citizen with high quality and affordable medical care by 2020 . However, two major puzzles surround Chinese health care on the eve of these new policy interventions:

1. Why did changes in the health care system precipitated by market reforms not lead to the kind of deterioration in the health of Chinese citizens that market reforms produced in Eastern Europe and the former Soviet Union?

2. In view of the increased inequalities in access to, and insurance coverage for, medical care since 1978, and particularly the growing rural-urban gap, why do Chinese villagers and migrants rate their current health better than do urban citizens?

These two puzzles are examined using health and other national trend indicators as well as data from a 2004 national survey of a representative sample of Chinese adults. Implications of this analysis for China's new health system reform efforts are discussed.
\end{abstract}

\footnotetext{
${ }^{*}$ Helpful suggestions were received from Judith Banister, Jason Beckfield, Cai Yong, Jieming Chen, Karen Eggleston, Daniel Goodkind, Patrick Hamm, Albert Hermalin, Arthur Kleinman, Sing Lee, Wang Feng, and Zachary Zimmer, none of whom are responsible for the resulting paper. Research assistance was provided by DongKyun Im.
} 


\section{The Impact of China's Market Reforms on the Health of Chinese Citizens:}

\section{Examining Two Puzzles}

During China's socialist period (roughly from 1955 to 1978) that society earned widespread

praise for developing basic health insurance and medical care institutions that at relatively low cost made health care available to virtually the entire population. China made substantial progress against major infectious diseases, produced large improvements in life expectancy, and made China's primary causes of mortality increasingly resemble those of a developed rather than a developing society. ${ }^{1}$

China launched a program of gradual but eventually fundamental market transformation in 1978, more than a decade before market reforms were initiated in the former Soviet Union and its satellites. As in Eastern Europe, market reforms undermined the health care institutions established under socialism, thus threatening the progress that had been made in citizen health. Within a few years, China went from having more than $90 \%$ of the population covered by medical insurance to having a majority (in the countryside, about $90 \%$ ) uncovered and having to pay for medical care out of pocket. ${ }^{2}$ Market reforms also produced escalating costs and fees for medical treatments, tests, and prescriptions as doctors and hospitals scrambled to cover their costs and generate profits, thus making it harder for many Chinese to afford the medical services they needed. In addition, the distribution of incomes in China widened sharply, with the poor and the newly unemployed sometimes foregoing needed treatment even as the newly wealthy were spending lavishly on cosmetic surgery and other elective procedures. ${ }^{3}$ By the early

\footnotetext{
${ }^{1}$ For example, the infant mortality rate fell from 200 to 34 per 1000 live births, and life expectancy increased from about 35 to 68 years from 1955 to 1982, even while China spent only about 3\% of GDP on health care. William Hsiao, "Transformation of Health Care in China," New England Journal of Medicine, 310 (1984): 932-36. For the changed mortality pattern in the Mao era, see Judith Banister and Samuel Preston, "Mortality in China," Population and Development Review, 7 (1981): 98-110. A more recent analysis indicates that Chinese government reports at the time exaggerated the life expectancy gains during the Mao era. The adjusted estimate for the late-Mao era is 60 rather than 68 years - still impressive, but not as much so as previously assumed. See Judith Banister and Kenneth Hill, "Mortality in China 1964-2000," Population Studies, 58(2004): 55-75. Mao's socialism also produced a mortality spike in 1959-1961 which these estimates miss, with more than 30 million excess deaths occurring as a result of the failed Great Leap Forward campaign. See Dali Yang, Calamity and Reform in China (Stanford, CA: Stanford University Press, 1996).

${ }^{2}$ Winnie Yip and William Hsiao, "The Chinese Health System at the Crossroads," Health Affairs, 27(2008), 461. See also the figures on medical insurance coverage in 2004 in Table 1 of the current paper.

${ }^{3}$ In terms of income distribution, China went from a modest estimated Gini coefficient in 1981 of .29 to .45 or even higher by 2002. See the discussion in Martin King Whyte, Myth of the Social Volcano (Stanford: Stanford
} 
years of the new millennium there was widespread criticism of the state of health care in China. Many citizens and observers voiced the lament that seeking medical care had become very difficult and expensive (kanbing nan, kanbing gui). ${ }^{4}$

Rising criticism of the problems unleashed by market reforms reached a crescendo in 2005 when a government report concluded that post-1978 reforms in health care had been a failure. ${ }^{5}$ By that time new efforts were already underway to address these problems. In particular, a major effort was launched after 2003 to build a new network of village medical insurance plans to replace the cooperative medical insurance schemes that had collapsed during the early 1980s. Major increases in government funding of health care were also launched, and in 2009 the government announced a determination to see that every Chinese citizen is provided with high quality and affordable medical care by 2020 . Laudable as these new initiatives are, we are left with two puzzles about China's health sector on the eve of these recent efforts: (1) Why, despite rising medical care costs and collapsing insurance coverage, did China not experience the deterioration in citizen health and life expectancy that occurred in Russia and many other post-socialist countries of Eastern Europe? (2) Why, despite the increased inequality in medical insurance coverage and ability to pay medical fees, particularly across the rural-urban divide, do villagers and migrants rate their current health better than do urban citizens?

\section{Post-Socialist Health Status and Life Spans: How and Why Is China Different?}

In Eastern Europe after 1989 and in the countries that emerged after the break-up of the Soviet Union in 1991, the post-socialist transition provoked a health crisis. The magnitude of the health crisis in

University Press, 2010). According to the results of a health survey in 2003, nationally $20.7 \%$ of respondents reported refusing to be hospitalized due to financial reasons, $18.7 \%$ did not seek medical care when ill for the same reason, and $27.7 \%$ reported seeking early discharge when they were hospitalized due to financial worries. Figures cited in Winnie Yip, "Disparities in Health Care and Health Status: The Rural-Urban Gap and Beyond," in Martin K. Whyte, ed., One Country, Two Societies: Rural-Urban Inequality in Contemporary China (Cambridge, MA: Harvard University Press, 2010), Table 7-4.

${ }^{4}$ See Karen Eggleston, “Kanbing Nan, Kanbing Gui: China's Healthcare System Reforms, 1980-2007,” in Jean Oi, Scott Rozelle, and Xueguang Zhou, eds., Growing Pains: Tensions and Opportunities in China's Transition (Washington, DC: Brookings Institution, 2010).

${ }^{5}$ Guowuyuan Fazhan Yanjiu Zhongxin Ketizu (Study Group of the Development Research Center, State Council), Dui zhongguo yiliao weisheng tizhi gaige de pingjia yu jianyi (gaiyao yu zhongdian) [Evaluation and Recommendations for the Reform of China's Medical and Health System (Outline and Main Points)] (Beijing: Xinhuawang, 2005). Subsequently the Minister of Health argued that it was an exaggeration to claim that health reforms had been a failure. 
that part of the world can be seen in the trends in overall life expectancy at birth, as shown for selected countries in Figure 1. ${ }^{6}$ (The years since reform in the $\mathrm{x}$-axis of Figure 1 refer to timing in relation to the onset of market reforms - the 0 year is 1989 for Eastern Europe, 1991 for the countries that emerged from the Soviet Union, and 1978 for China.) In some countries, such as Poland and Hungary, the post-socialist downturn in life expectancy was minor and temporary and was followed by subsequent and substantial improvement. However, for other countries, the most notable being Russia, there were major and sustained declines in life expectancy, with pre-transition levels still not regained by 2006 or 2007, the final years for which data are available. ${ }^{7}$

(Figure 1 about here)

The trend line for life expectancy at birth for China looks very different. Figure 1 contains two variants, unadjusted figures drawn from life tables calculated from the Chinese censuses of 1982, 1990, and 2000, and adjusted estimates incorporating corrections for underreported mortality, based upon the work of Judith Banister and Kenneth Hill. ${ }^{8}$ Although Chinese estimates are available for fewer years than for Eastern Europe (here and subsequently this term refers to the former Soviet Union as well as its satellite countries), the contrast is very clear. There is no sign of any post-transition dip in life expectancy for China, and in fact a sustained and substantial improvement is visible, from an estimate of 60 circa

\footnotetext{
${ }^{6}$ The statistics in Figure 1 for selected East European and post-Soviet countries are taken from the World Health Organization European Health for All Database, available online at data.euro.who.int/hfadb/tables/, accessed on 11 Oct. 2009. We thank Patrick Hamm for referring these data to us.

${ }^{7}$ For analyses of these Easter European life expectancy trends, see Elizabeth Brainerd and David M. Cutler, "Autopsy on an Empire: Understanding Mortality in Russia and the Former Soviet Union," Journal of Economic Perspectives, 19 (2005): 107-30; Lawrence King, Patrick Hamm, and David Stuckler, "Rapid Large-Scale Privatization and Death Rates in Ex-Communist Countries: An Analysis of Stress-related and Health System Mechanisms," International Journal of Health Services, 39 (2009): 461-89. Other indicators besides life expectancy, such as suicide rates, also reflect the health crisis in the region. See the discussion in King, et al. (However, it should be noted that for Russia and some other parts of the former Soviet Union, the decline in life expectancy, for males at least, preceded 1991. See the discussion in Brainerd and Cutler.)

${ }^{8}$ The unadjusted estimates are drawn from calculations provided by Cai Yong, which in turn draw in part on Huang Rongqing and Liu Yan, Mortality Data of China's Population (in Chinese), (Beijing: China Population Press, 1995). The adjusted figures are based upon Banister and Hill, "Mortality in China 1964-2000" and further work by Judith Banister along the same lines (personal communication). It should be noted that for China, Banister's estimate for 2005, 27 years after the onset of reforms (73.7 years), is not shown in Figure 1 and represents a further improvement in life expectancy to levels surpassing many of the East European cases. This is a dramatic convergence given that China still has a much larger agricultural sector than the comparison countries and had much lower life expectancy prior to the reforms. (The U. S. Census Bureau provides slightly lower current estimates of life expectancy at birth for China, 72 in 2005 and 73 in 2009. See www.census.gov/ipc/www/idb/country.php, accessed on 9 Dec. 2009.)
} 
1973 (prior to the transition) to about 71 in 2000 (based upon the adjusted estimates). Furthermore, the research upon which these estimates are based indicates that the health gains in China were very broadly shared within the population and are reflected in other indicators, such as declining infant and maternal mortality rates, increasing child height, and reduced tuberculosis prevalence, although obviously some threats to health have increased during this period (e.g., SARS, AIDS, rising traffic accident and air pollution-related deaths). ${ }^{9}$ The trends in Figure 1 provide our first puzzle: Why did China not experience the negative impact on health of its post-socialist transition, despite drastically reduced health insurance coverage, medical cost escalation, and rising income gaps?

Our answer to this first puzzle must of necessity be speculative. There are obvious and important differences between the post-socialist transitions in China versus Eastern Europe that likely played key roles in enabling China to avoid the negative health trends visible in Eastern Europe. First and most obvious is the fact that China has experienced a sustained economic boom, averaging close to $10 \%$ economic growth rates over three decades, avoiding the economic depressions that accompanied the dismantling of socialism (and the collapse of Communist Party rule) in Eastern Europe. Furthermore, this economic boom was accompanied by major and substantial improvements in average living standards and huge reductions in the proportion of the Chinese population living in poverty, particularly during the earliest years of the reforms, from 1978 to $1985 .^{10}$

As elsewhere around the world, rising living standards have multiple and largely positive implications for citizen health, as captured in the phrase, "wealthier is healthier."11 For example, as chronic malnutrition is eased and diets improve from the very limited levels that characterized China in

\footnotetext{
${ }^{9}$ See, for example, the evidence presented in Banister and Hill, "Mortality in China;" Yip, "Disparities in Health Care and Health Status."

${ }^{10}$ During the period from 1978 to 1985 , there was an astonishing tripling of the real income of China's rural residents and a reduction of the urban-rural income ratio from close to 3:1 to below 2:1. As a result, more than 200 million Chinese were lifted out of poverty, according to estimates from the World Bank. See the discussion in Dennis Yang and Cai Fang, "The Political Economy of China’s Rural-Urban Divide” and Scott Rozelle, Linxiu Zhang, and Jikun Huang, "China's War on Poverty,” both in Nicholas Hope, Dennis Yang, and Mu Yang Li, How Far Across the River? Chinese Policy Reform at the Millennium (Stanford: Stanford Univ. Press, 2003). Since 1985 the urban-rural income ratio has generally been increasing, to levels of 3:1 or higher in the new millennium. During this period average rural incomes have continued to increase, but not as fast as urban incomes.

${ }^{11}$ Lant Pritchett and Lawrence Summers, “Wealthier is Healthier," Journal of Human Resources, 31 (1996): 841-68.
} 
the 1970 s, citizen health improves, at least as long as obesity remains uncommon. ${ }^{12}$ As rising incomes and other changes produce increases in educational attainment and literacy rates, health knowledge and healthy behavior are enhanced. As communities that were isolated and lacked electricity and running water become richer and obtain electricity, telephone, and electronic media connections to the outside world, as well as running water and better housing and sanitation facilities, local health conditions are improved. ${ }^{13}$ And of course as incomes rise and people who lacked disposable incomes and savings have more resources, the potential to pay for needed medical care is enhanced. An examination of variations in life expectancy trends across Eastern Europe reveals that other things being equal, those countries that recovered economically and resumed growth had better life expectancy trends than other countries in that region. ${ }^{14}$

A second key difference between China and Eastern Europe is that China rejected a "big bang" approach of rapid privatization in favor of a gradual sequencing of market reforms. Furthermore, the particular way in which the planned economy was dismantled in China involved a dual track approach in which initially state enterprises and state employment were preserved even as private, village-owned, and foreign firms were allowed to spring up "outside of the plan.” As a result of this approach, the standards of living of those in the state sector were largely preserved until the mid-1990s, avoiding until then the mass layoffs, firm closures, and withheld wages that became endemic in the East European transition at the outset. The result has been characterized in one influential analysis as "reform without losers," an approach that initially cushioned the lives and livelihoods of those accustomed to socialist employment. ${ }^{15}$ Since analyses of the variable impact of the transition in Eastern Europe indicate that the speed and scale

\footnotetext{
12 See Barry Popkin, G. Keyou, Zhao Fengying, Xuguang Guo, Ma Haijiang, and Namvar Zohoori, "The Nutrition Transition in China: A Cross-sectional Analysis," European Journal of Clinical Nutrition, 47 (1993): 333-46. Obesity is a growing problem in China in recent years, but mainly among the minority of urban families who have attained middle class or higher living standards.

${ }^{13}$ One study found that the level of such community amenities had a net effect of reducing the mortality risk of older Chinese. See Zachary Zimmer, Toshiko Kaneda, and Laura Spess, "An Examination of Urban versus Rural Mortality in China Using Community and Individual Data," Journal of Gerontology, 62B (2007): S349-57.

${ }^{14}$ See the analyses presented in King, et al., "Rapid Large-scale Privatization and Death Rates."

${ }^{15}$ See Lawrence Lau, Yingyi Qian, and Gerard Roland, "Reform without Losers: An Interpretation of China's Dual Track Approach to Transition," Journal of Political Economy, 108 (2000): 120-43. See also Barry Naughton, Growing out of the Plan: Chinese Economic Reform, 1978-1993 (Cambridge, UK: Cambridge Univ. Press, 1995); Martin K. Whyte, "Paradoxes of China's Economic Boom,” Annual Review of Sociology, 35 (2009): $371-92$.
} 
of privatization of firms and property were associated with increased anxiety and stress that had negative impacts on life expectancy, the fact that China's reforms avoided rapid and large scale privatization may help explain the more favorable health outcomes. ${ }^{16}$

A third key difference between China and Eastern Europe is that China has been undergoing a major rural-urban transition during the reform era, a process completed earlier in most of Eastern Europe. Whatever the merits of the basic-level health institutions in rural China during the Mao era, villagers in that era were prohibited from migrating to the city and were only referred to county hospitals for treatment with the approval of minimally trained barefoot doctors, while the proportion of the population living in cities barely budged upward under socialism (with less than $20 \%$ of Chinese being urban citizens in 1978). China's cities and urban residents benefited by the presence of the best hospitals and substantially higher levels of medical personnel and institutions. (China in both the late-Mao era and today has had one of the largest rural-urban gaps in the world in incomes, development levels, and (acilities. $)^{17}$

The post-1978 reforms, including the de-collectivization of agriculture and the relaxation of migration restrictions, have altered the situation in multiple and fundamental ways. As we approach the close of the first decade of the new millennium, close to $50 \%$ of China's population now resides in urban areas. Furthermore, with the shift toward out-of-pocket payment for medical care and the weakening of the mandatory health referral system of the Mao-era, residents of villages and small towns who have serious medical problems can now seek care in urban hospitals rather than in their local clinics. Even though by several indicators there has been deterioration in the rural-to-urban ratios of medical facilities and personnel since 1978, a much larger proportion of China's population today can avail themselves of

\footnotetext{
${ }^{16}$ See again King, et al., "Rapid Large-scale Privatization and Death Rates." There is no evidence for China of the surges in alcohol abuse, suicide, and other negative reactions to extreme stress and anxiety that occurred in Russia and other parts of Eastern Europe. (On the rough stability of suicide rates in China, see Michael Phillips, Xianyun Li, and Yanping Zhang, "Suicide Rates in China, 1995-99," The Lancet 359(2002): 835-40.) Since the mid-1990s there has been a substantial down-sizing of state enterprises, with significant increases in unemployment and even some firm closures, so the phrase "reform without losers" is no longer applicable. However, for the bulk of the Chinese population reforms have meant improved employment opportunities, particularly for the roughly 300 million rural Chinese at any one time in recent years who have left farming for either rural factory employment or migrant labor in the cities.

${ }^{17}$ See Yang and Fang, "The Political Economy of China's Rural-Urban Divide."
} 
medical care in favored urban hospitals and receive treatment from urban doctors - provided, of course, they can pay the bills. ${ }^{18}$ In short, the rural-urban transition underway in China since 1978 means that a much higher proportion of the population benefits from the superior medical facilities and conditions that less than one fifth of Chinese citizens (urban residents) enjoyed in the late-Mao era. ${ }^{19}$

Perhaps some other factors also helped drive the improvements in health indicators in China since 1978, such as intensified immunization drives against common diseases and renewed public health campaigns directed at endemic infectious diseases and community sanitation problems, as well as antipoverty campaigns directed at the poorest counties and communities. ${ }^{20}$ However, since other trends within the health policy sphere, such as the collapse of medical insurance coverage, presumably threaten citizen health, on balance it seems unlikely that the Chinese government's health efforts since 1978 have been an important net positive influence explaining China's improved health profile. ${ }^{21}$ Rather, it would appear that the answer to our first puzzle is that both the rate and nature of China's post-1978 economic development trajectory have counteracted and indeed overwhelmed the negative consequences stemming from the weakening of socialist health care institutions, leading to the major gains in citizen health that

\footnotetext{
${ }^{18}$ On rural residents bypassing local facilities to seek care (outpatient as well as inpatient) from urban hospitals, see David Blumenthal and William Hsiao, "Privatization and its Discontents-The Evolving Chinese Health Care System," New England Journal of Medicine, 353 (2005): 1165-70. The improvements in community and household infrastructure mentioned earlier, including better highway connections, improved long-distance bus service, and increases in private vehicle ownership, have facilitated this trend toward seeking medical care outside the local community. Perhaps because of these changes, one study found that variables measuring the number of local medical facilities and distance to the nearest such facility did not have a significant net impact on mortality risk in the communities studied. See Zimmer, "An Examination of Urban versus Rural Mortality."

${ }^{19}$ However, this flocking of rural residents to urban medical facilities for treatment obviously aggravates the imbalances and excess demands that contribute to the sentiment that kanbing nan, kanbing gui.

${ }^{20}$ The consequences of fertility declines produced by draconian family planning enforcement in China since the 1970s can be debated. Banister and Hill ("Mortality in China 1964-2000") stress the beneficial effects for women of fewer pregnancies occurring early, but also note the increases in female infant mortality the same campaigns produced. On balance it is doubtful whether the net effect has boosted life expectancy at birth.

${ }^{21}$ One recent analysis rated China a lowly 144 out of 191 WHO member states in terms of the performance of its health care system (based upon five indicators: overall level of population health, health inequalities within the population, overall level of health system responsiveness, distribution of responsiveness within the population, and distribution of the financial burden of health care within the population), below all of the East European countries with which it is compared in Figure 1 (Russia comes closest, at rank 130). See Ajay Tandon, Christopher Murray, Jeremy Lauer, and David Evans, "Measuring Overall Health System Performance for 191 Countries," WHO working paper \#30, n.d., available at http://www.who.int/healthinfo/paper30.pdf , accessed on 17 Oct. 2009. For a somewhat more positive view of the government's role in the improvement of health indicators, see Yanzhong Huang, The Paradox of State Power: Political Institutions, Policy Process, and Public Health in Post-Mao China, unpublished doctoral dissertation, Department of Political Science, University of Chicago, 2000.
} 
distinguish China from the post-socialist societies of Eastern Europe. The average Chinese citizen has become healthier as Chinese families and communities have become wealthier, despite the fact that the health care system in some respects is performing more poorly than in the late Mao era. ${ }^{22}$

\section{Why Don't Chinese Villagers and Migrants Feel Sicker than Urbanites?}

At the aggregate level the harmful impact of market reforms was mitigated in China, with estimates of life expectancy and other health indicators improving after 1978, but what about rising inequality? One might expect to find the health status of poor and disadvantaged Chinese and their better off fellow citizens diverging. However, data from a national survey in China in 2004 contradict this scenario, with villagers and urban migrants reporting better health status than do urban citizens. We know there is a virtually universal pattern around the world, including in advanced societies with universal health insurance coverage, for high status citizens to report better health than low status ones. ${ }^{23}$ In other words, even in the absence of the kinds of inequality trends unleashed by market reforms, social status and health are positively correlated. Is China an exception to this world-wide pattern?

The data to be analyzed here come from the 2004 national China Survey on Attitudes toward Inequality and Distributive Justice. Using spatial probability sampling methods, 3,267 respondents representative of all non-institutionalized adults between the ages of 18 and 70 were interviewed to probe popular attitudes toward current inequality patterns. ${ }^{24}$ While the major focus of the survey was on

\footnotetext{
${ }^{22}$ Even in the United States, research suggests that of the roughly 30 years increase in life expectancy that occurred in the $20^{\text {th }}$ century, perhaps only 5 to 7 years can be attributed to improvements in preventive or therapeutic medical care. See John Bunker, Howard Frazier, and Frederick Mosteller, "Improving Health: Measuring Effects of Medical Care," The Milbank Quarterly, 72 (1994): 224-58.

${ }^{23}$ There is an abundant research literature documenting the universality or near universality of a positive correlation between a wide range of socio-economic status characteristics (income, education, occupational status, etc.) and a variety of measures of physical and psychological health. For a recent review, see Irma Elo, "Social Class Differentials in Health and Mortality: Patterns and Explanations in Comparative Perspective," Annual Review of Sociology, 35 (2009): 553-72.

${ }^{24}$ Whyte served as the principal investigator for the survey, with the research team including Albert Park, Wang Feng, Jieming Chen, Pierre Landry, and Chunping Han on the Harvard-based team. We collaborated with the Research Center for Contemporary China (RCCC) of Peking University, which carried out the survey fieldwork, and our RCCC co-investigators were led by Shen Mingming, Yang Ming, and Yan Jie. Primary funding for the survey project was provided by the Smith Richardson Foundation, with supplementary funds coming from the Weatherhead Center for International Affairs at Harvard, the Center for the Study of Democracy at the University of California at Irvine, and from Peking University. Spatial probability sampling is a technique replacing the former reliance of most China surveys on sampling from household register records, with the latter no longer viable due to population
} 
attitudes toward income and other inequalities in contemporary China, the survey questionnaire included a limited number of questions related to health. These questions form the basis for the analyses presented here.

\section{Variations in Health Concerns and Current Health Status}

The 2004 survey contained a question about self-assessed current physical health; eight questions about the frequency of experiencing various emotional symptoms or problems; whether or not respondents currently have public medical insurance coverage (shehui yiliao baoxian; privately purchased health insurance, a recent and so far uncommon phenomenon in China, was not inquired about); questions about individual or family experiences within the last three years of serious illnesses, deaths, and difficulties paying medical bills; a question about the severity of worries about paying for future medical bills; and a question about views on the extent to which the government versus individuals and families should be responsible for health care. Brief descriptions of these items are provided in Appendix Tables A and B. ${ }^{25}$

As a first step, we examine social background variations in medical cost anxieties and in health status by cross-tabulating responses to health questions with gender, household registration type (rural, migrant, or urban), family income level, respondent educational attainment, and region. The results are shown in Tables 1 and 2. First, in regard to whether respondents are covered by medical insurance, we see in Table 1 that there is no significant gender difference (see columns 1 and 2), but large and statistically significant differences by social status. Migrants are the category least likely to have medical insurance (only 9\%), with rural residents following closely behind (only 15\%). Slightly more than half of respondents with urban registrations (51\%), in contrast, have medical insurance. The gaps in insurance

mobility. Spatial probability sampling involves the use of maps and population distribution data to select geographical sampling points with probability proportional to population size and then to use geographic positioning system devices to send interviewing teams to the selected locales in order to attempt interviews with one adult per household within a designated perimeter around each point. The response rate in the 2004 survey was $75.2 \%$. For more detail on the survey, see Whyte, Myth of the Social Volcano.

${ }^{25}$ Our survey included an over-sampling of China's urban population in order to enable us to analyze rural and urban responses separately. In reporting the overall distributions in Appendix Tables A and B, we use sampling weights to correct for this over-sampling, thus yielding figures designed to represent the overall population of Chinese adults between the ages of 18 and 70 . 
coverage across respondents grouped in terms of other status measures are also large- from $13 \%$ to $53 \%$ across four family income categories, from $15 \%$ to $60 \%$ when comparing the worst and best educated, and from $16 \%$ to $38 \%$ when comparing residents of Western provinces with Eastern provinces. Not surprisingly, there are also small gaps by gender but large gaps according to social status for both past experiences of difficulties paying for medical emergencies (columns 3 and 4) and worries about being able to pay for future medical treatment (columns 5-7). These are the kinds of inequalities in concerns about medical care the post-2003 health care reform efforts are designed to redress.

(Table 1 about here)

Finally, in columns 8-12 we see a similar pattern for views on responsibility for health care. Men and women do not differ significantly on whether the government or individuals and families should mainly be responsible, but there are significant differences for each of the four status measures. Favoring state responsibility is associated with high status groups, with urban citizens, upper income respondents, the well educated, and residents of Eastern provinces all more likely than others to favor state rather than individual responsibility for health care.

When we turn to measures of past medical problems and present health status, the picture looks more complicated, as shown in Table 2. We do not find a consistent pattern of the social groups that lack medical insurance or have health care worries reporting worse health experiences and health status. The first pattern to note is that although male and female respondents do not differ significantly in terms of whether they had serious illnesses or deaths in their families within the past 3 years (see columns 1-4), we do find a pattern that is commonly reported in studies of health self-ratings in other countries-for women to be significantly more likely than men to report poor physical and emotional health. ${ }^{26}$

\section{(Table 2 about here)}

Respondents with different household registration statuses do not differ significantly in terms of family incidence of serious illnesses and deaths (columns 1-4), nor do they differ significantly in terms of

\footnotetext{
${ }^{26}$ See again Elo, "Social Class Differentials in Health and Mortality."
} 
self-rated emotional distress symptoms (columns 10-13). ${ }^{27}$ They do differ significantly in terms of selfrated physical health (columns 5-9), but not in the expected direction. Contrary to expectations, the proportion rating their health as good or very good ranges from $60 \%$ for migrants to $55 \%$ for rural residents to only $50 \%$ for favored urban residents. Perhaps the superior self-ratings of migrants are explained at least in part by their generally younger ages (a possibility we will examine below), ${ }^{28}$ but even so it is striking that the two rural-origin groups rate their health better than urbanites. This is the disparity that is at the center of our second puzzle.

When examined in terms of other status measures - for family income, respondent educational attainment, and region of residence - there are fewer surprises. For these three status variables we find the pattern found in other societies: of more reported serious family illnesses and deaths among those with low incomes, low education, and residence away from the coast, although not all of these differences are statistically significant (and slightly more negative family health experiences occurred within the last three years to residents of Central provinces than to residents of Western provinces.) Self-rated physical health and emotional health are also generally better for respondents in high income families, with high levels of education, and for those who reside in Eastern provinces, although there are some departures from the expected linear and positive relationship between status and health. Specifically, upper middle school graduates have slightly worse self-ratings of physical and emotional health than either lower middle school graduates or those who attended college (see the fourth panel in Table 2, rows 2-4). Even for these social status measures, however, the disparities in health experiences and self-ratings between low and high status groups are more narrow than the comparable disparities in medical insurance coverage by those same characteristics (compare Table 2 with columns 1 and 2 in Table 1). Correlation and Regression Analyses of Health Access and Health Status

\footnotetext{
${ }^{27}$ The emotional distress scale shown in Table 2 is a truncated, four category version of a summary scale constructed from the eight items shown in the lower portion of Appendix Table B. See the discussion in note 30 . ${ }^{28}$ The better health self-assessments of migrants could also be attributable to what is called the "healthy migrant effect," with migrants tending to be healthier than those who remain behind in the villages, as well as leaving the cities when they become ill or suffer injuries in order to recuperate back in the countryside. See comments on this possible explanation later in this paper.
} 
Since our social background measures in Tables 1 and 2 are entangled in complex ways, we need to disentangle these complexities. In particular, we want to know whether the lack of a significant difference in self-rated emotional health and the significantly better self-rated physical health of ruralorigin groups are spurious results produced by the influence of other background characteristics of respondents. In order to answer this question we turn to correlation and regression analyses of five of our survey-based health measures: whether the respondent has public medical insurance coverage, their selfrated physical health, their self-rated emotional distress level, their worries about paying for future medical bills, and their views on state versus individual responsibility for health care. ${ }^{29}$

In order to examine how these five health measures are related to background characteristics, we utilize a larger number of predictors than in Tables 1 and 2. As before, we distinguish three household registration categories: rural residents (rural), rural migrants residing in urban areas (migrant), and urban citizens (urban).$^{30}$ We also employ a range of other objective background characteristics: gender (female $=1$; male $=0$ ), age, age-squared divided by 100 (to help us detect curvilinear associations with age), number of years of schooling, marital status (married=1; otherwise $=0$ ), ethnicity (Han=1; otherwise $=0$ ), the log of the respondent's reported total family income in the previous year, membership in the Chinese Communist Party $(\mathrm{CCP}$; yes $=1 ;$ no=0), past or present work in a state-owned enterprise $(\mathrm{SOE} ; \mathrm{yes}=1 ; \mathrm{no}=0)$, and whether the respondent has public medical insurance coverage (yes $=1 ;$ no $=0$ ). We also employ two geographic location measures: regions as defined by China's National Statistics

\footnotetext{
${ }^{29}$ Health insurance coverage is a dummy variable, with yes $=1$ and no $=0$. Strictly speaking we should be performing logistical regression with a binary dependent variable, but we present here the ordinary least squares regression for comparability and because the results are much the same. Physical health self-rating is based on a five point scale ranging from $1=$ very poor to $5=$ very good and is treated as if it were an interval measure. The emotional distress scale is derived from the questions displayed in the lower panel of Appendix Table B. The two positive statements (I feel fortunate; I feel life is very happy) were reversed, and then the eight items were summed to create the scale with a reliability of $\alpha=.77$. (Table 2 used a truncated version of this measure, with scores divided into four categories.) The measure of worries about paying for future medical bills was based on the single question shown in the next to last row of Appendix Table A, but in reverse order, ranging from $1=$ no worries at all to $3=$ serious worries, and again this is treated as if it were an interval scale. Finally, the state versus individual responsibility for health care is the item shown in the final row of Appendix Table A, ranging from 1=state fully to $5=$ individual fully, and again treated as if it were an interval scale.

${ }^{30}$ In statistical analyses three dummy variables are used, and in regression analyses, urban is the omitted reference category.
} 
Bureau (Eastern, Central, or Western provinces ${ }^{31}$ ) and an index of the relative impact of market reforms in the province in which the respondent resides. ${ }^{32}$ Finally, as past research indicates that subjective measures of social status may have as much impact on health outcomes as objective ones, we include measures of the respondent's report of how their family was doing economically compared to five years earlier (ranging from $1=$ much worse to $5=$ much better) and of their current living standard relative to four different local reference groups (relatives, former schoolmates, workmates, and neighbors, in each case ranging from $1=$ much worse to $5=$ much better, and then averaged) ${ }^{33}$

Table 3 presents the results of our analyses of variations in our five health outcome measures. (Note that for insurance coverage and physical health [columns 1-4], a high score indicates positive health, while for emotional distress and bill worries [columns 5-8], a high score indicates negative health. In columns 9-10 a positive coefficient indicates greater stress on individual responsibility for health care.) We first display the bivariate correlation coefficients of these five measures with each background variable, before controlling for the influence of other predictors. Next we display the corresponding standardized ordinary least squares (OLS) regression coefficients, a procedure that shows the net influence of each individual predictor while controlling statistically for the influence of all of the other predictors in the regression model. ${ }^{34}$

\footnotetext{
${ }^{31}$ As with household type, these regions are used to construct dummy variables, and in regression analyses, the East region is the omitted reference category.

32 The marketization index is derived from a Chinese study which ranked all of China's provinces in terms of twenty-three distinct aspects of market reform implementation and impact, each ranging from 0 to 10 , with our index a mean of these separate aspects, ranging from 3.61 for Guizhou to 9.74 for Guangdong. See Fan Gang and Wang Xiaolu, Zhongguo shichanghua zhishu-Gediqu shichanghua xiangdui jincheng 2004 niandu baogao (Marketization Indexes for China: Report on Relative Progress toward Marketization in Various Localities in 2004). (Beijing: Economic Science Press, 2004).

${ }^{33}$ Since we don't presume that these subjective status measures can influence whether the respondent has medical insurance coverage, they are omitted from the statistical models for the health insurance coverage measure.

${ }^{34}$ Since technically only the emotional distress scale is an interval measure, while our other health measures are ordinal measures, we also computed the appropriate ordinal regression statistics (logistic or ordered logit) for those measures. Since the findings were virtually identical, for simplicity and comparability we display only OLS regression results in Table 3. We display standardized, rather than un-standardized, regression coefficients because we are interested in examining the relative strength of different predictors, not in determining how much change in each health outcome measure is produced by a change of one unit in each predictor variable. For the geographic predictors (region and the marketization scale), there is a clustering tendency in the survey, since all respondents interviewed in one sampling point have identical values on these variables, a tendency that violates the assumptions of OLS regression (by underestimating standard errors). We checked our results with multi-level statistical
} 
(Table 3 about here)

The first two columns in Table 3 show the influence of various background predictors on whether the respondent has public medical insurance coverage or not. The regression coefficients in column 2 yield few surprises. Compared with urban citizens, both villagers and migrants are significantly less likely to have coverage. Even when household types are controlled for, other indicators of social status are significantly associated with medical insurance coverage, with the well-educated, those with high family incomes, CCP members, and those with ties to SOEs (and also females and married individuals) favored in this respect. Taken together the predictors we use in the regression model explain $29 \%$ of the variation in who has medical insurance coverage. These results confirm the figures in Table 1--high status respondents were in 2004 likely to have medical insurance coverage, while their low status counterparts were not.

However, the results in the remainder of Table 3 reinforce the greater complexity we saw earlier. Turning first to the predictors of self-reported physical health (in columns 3 and 4), once we control for other variables via regression, we see several expected patterns - for those who are better educated, are Han, are CCP members, have ties to SOEs, and who are covered by health insurance to report significantly better health than other respondents, while women report poorer health. In addition we see strong associations with the two subjective status measures, with those who say their families are doing better than they were five years earlier and those who report higher status than others in their local reference groups rating their current physical health better. ${ }^{35}$ However, other patterns are less expected. There is no net association between family income and self-reported health, once other measures are

procedures, and "downgraded" in Table 3 those coefficients which were no longer statistically significant. The result of this correction was that none of the geographic predictors employed in the regressions retained conventional significance levels.

${ }^{35}$ As in other societies, there is no way to tell the dominant direction of causation in such associations between status and health. Does high status convey health benefits, or do the healthy achieve higher status in society? 
controlled for statistically, and there is some evidence of a curvilinear association with age, with the middle-aged rather than the elderly reporting the worst physical health. ${ }^{36}$

However, the most surprising patterns are in the first panel of Table 3, confirming our second puzzle. The association between rural origins and positive self-reported physical health is not spurious, since even when we control for other background factors, both villagers and migrants rate their current physical health significantly better than do urban citizens.

Broadly speaking, we see similarly mixed patterns in models explaining variation in emotional distress scores (in columns 5 and 6). In contrast to physical health, years of education and CCP membership are not significant predictors of levels of self-reported emotional health, but women are again more likely to report poor emotional health, while married people, ethnic Han, and those who are covered by medical insurance are less likely to do so. Once again subjective social status measures are strong predictors--those who feel their families are doing better than five years earlier and better than their peers are significantly less likely to report emotional problems. The curvilinear age pattern is even stronger for emotional than for physical health, with the middle aged most likely to report emotional problems. ${ }^{37}$

Once again our major focus is on the figures in the first panel of Table 3. Once we control for other factors, both rural residents and migrants report significantly better emotional health than urban citizens. Note that in Table 2 and in the correlations in column 5 of Table 3 emotional distress scores do not differ significantly across household registration types. Once we control for other social background factors, however, a net tendency for rural-origin to be associated with significantly better emotional health

\footnotetext{
${ }^{36}$ The negative association between age and physical health in combination with the positive association with agesquared indicates a curvilinear relationship, although only the former is statistically significant. We also expect to find a positive association between being married and self-reported physical health, but the net association here is close to zero.

${ }^{37}$ Once again family income, generally a strong predictor of health outcomes in other societies, is not a significant net predictor of the self-reported emotional health of China survey respondents.
} 
appears. Thus for both physical and emotional health, once we control for other social background predictors, villagers and migrants rate their health in 2004 better than do urban citizens. ${ }^{38}$

Our fourth health outcome measure, the level of worries about being able to pay for a future medical emergency, again displays both expected and unexpected patterns. Those with high incomes and with medical insurance coverage are as expected less worried about paying for future medical emergencies, as are those who feel that their families are doing better than five years earlier and better than their local peer groups, while women are slightly more likely to be worried on this score. And it is the middle aged rather than the elderly who are most worried about paying for future medical emergencies, net of other influences, repeating a pattern seen earlier.

Once again it is the associations in the first panel of Table 3 that are surprising. Net of other factors, villagers are significantly less likely than urban citizens to have anxieties about future medical expenses. Migrants do not differ significantly from urbanites on this question, but even this null finding is surprising. In sum, not only in regard to self-rated physical and emotional health, but also in regard to anxieties about future medical bills, China's rural-origin citizens give more positive responses than we would expect them to, given both the comparative evidence on status differentials in health in other societies and the diverging trends in incomes and health insurance coverage in China after market reforms.

The final health-related measure in Table 3 concerns who should have the major responsibility for health care, the government versus individuals and families (see columns 9-10). One might assume that disadvantaged groups would advocate government provision of health care, while their higher status fellow citizens would be more willing to take individual responsibility for medical bills. However, the

\footnotetext{
${ }^{38}$ We noted earlier that the "healthy migrant" effect might help explain migrants having better health status than urban citizens. See Therese Hesketh, Ye Xuejun, Li Lu, and Wang Hongmei, "Health Status and Access to Health Care of Migrant Workers in China," Public Health Reports, 123 (2008): 189-97. However, such a healthy migrant effect cannot explain why on both physical and emotional health measures, it is rural residents who give the most positive reports, net of other factors. Self-rated physical health and emotional distress measures are themselves strongly and negatively correlated $\left(\mathrm{r}=-.41^{* * *}\right)$. We know from research elsewhere that emotional distress can have a negative effect on physical health and that physical health problems can cause emotional distress. We do not include emotional distress in our regression model for physical health in Table 3, nor do we include physical health in our model for predicting emotional distress, since there are no sound reasons for deciding the causal direction in this reciprocal relationship.
} 
patterns in Table 1 contradicted this expectation, and the regression results in Table 3 reinforce this contradiction. To be sure, net of other factors those with high incomes, CCP members, and those who feel they are doing better than five years earlier and better as well than their peers tend to favor individual responsibility for health care. However, the most striking patterns again occur in the first panel of Table 3, where both villagers and migrants are significantly more likely than urban citizens to favor individual responsibility for health care. Furthermore, the net effect of being highly educated or having ties to a state-owned enterprise is to favor government rather than individual responsibility for health care. These latter patterns suggest the lingering influence of a tendency for those who were favored "supplicants to the socialist state" during the Mao era to prefer to rely on state largesse today, an explanation to which we return below. ${ }^{39}$

\section{Why Do China's Farmers and Migrants Report Better Current Health Status?}

How can we explain this unexpected pattern of villagers and migrants reporting better physical and emotional health than urban citizens? Is China an exception to the worldwide tendency for high status groups to be healthier than low status groups? Not really. For other status variables except household type, we see many positive associations between status and health in Table 3 . We also have abundant outside evidence that the health profile of rural Chinese is inferior to urban Chinese. For example, life expectancy estimates are higher in all periods for urban Chinese, and infant and maternal mortality rates are higher in the countryside, as is the prevalence of tuberculosis and other infectious diseases. ${ }^{40}$ In the emotional realm, we also know that China is distinctive in having substantially higher

\footnotetext{
${ }^{39}$ The phrase "supplicants to the socialist state" is adapted Deborah Davis, "Urban Families: Supplicants to a Socialist State," in D. Davis and S. Harrell, eds., Urban Families in the Post-Mao Era. (Berkeley: University of California Press, 1993).

${ }^{40}$ See Yip, "Disparities in Health Care and Health Status;" Zhongwei Zhao, "Income Inequality, Unequal Health Care Access, and Mortality in China," Population and Development Review, 32 (2006): 461-83; United Nations Development Program, Human Development Report China 2007/08: Access for All; Basic Public Services for 1.3 Billion People (Beijing: China Translation and Publishing Corporation, 2008); and Zimmer et al, "An Examination of Urban Versus Rural Mortality in China."
} 
suicide rates in rural than in urban areas. ${ }^{41}$ How can we account for the fact that Chinese of rural origin rate their health much more positively than their objective circumstances seem to warrant?

As in addressing the first puzzle, our answer to this question must be somewhat speculative. We start by noting again that our 2004 health measures are self-reported assessments and that we do not have blood or urine tests, physician exams, or other objective indicators of health status. This feature does not mean that such self-reported data are misleading or invalid as measures of current health status. In fact past studies in other societies indicate that the kind of survey-based self-assessments of current physical health such as we employ here are very accurate predictors of future mortality, perhaps even better than more objective measures. ${ }^{42}$ However, it nonetheless seems likely that subjective influences play a large role in shaping survey responses about current health status. ${ }^{43}$

How do subjective influences help explain why in 2004 villagers and migrants reported better physical and emotional health than urban citizens? $?^{44}$ In part this may be a matter of lower expectations of Chinese with rural roots, at least for self-assessed current physical health. They may be less likely than urbanites to view such things as headaches, chronically upset stomachs, and toothaches as problems that require medical treatment. Rural-origin respondents are also less likely than urbanites to be aware of health problems they have. Since they are much less likely than urban citizens to have health insurance and to receive regular physical examinations, as well as less exposed to mass media stories about societal

\footnotetext{
${ }^{41}$ See the evidence presented in Phillips, et al., "Suicide Rates in China, 1995-99." However, a disproportionate number of China's rural suicides represent reactions of young women to severe family conflicts, so this rural-urban disparity may not be a good objective indicator of more general and less severe patterns of anxiety and stress of the sort tapped by our survey questions.

${ }^{42}$ See, for example, E. Idler and Y. Benyamini, "Self-rated Health and Mortality: A Review of Twenty-seven Community Studies," Journal of Health and Social Behavior, 39 (1997): 21-37. For China one longitudinal study found that if a family member over age 50 was reported to be ill or had been sick during the prior four weeks, other things being equal they were more than twice as likely as others to have died by the later waves of the survey. See again Zimmer et al., "An Examination of Urban Versus Rural Mortality in China."

${ }^{43}$ The associations between our survey health measures and gender, age, and status compared with five years earlier and with peers all point to the role of subjective influences. In the case of age, the unexpected curvilinear trend, with the middle aged reporting the worse health and most health worries, may reflect the continuing impact of the disruptions of the Cultural Revolution (1966-76) on the lives and careers of those most affected (often referred to as China's "lost generation").

${ }^{44}$ It is worth noting that some objective differences in the typical situation of villagers and migrants versus urbanites should foster better health among the former groups, including higher levels of physical exercise, lower-fat diets, less exposure to air pollution, and less prevalent obesity. However, these advantages are unlikely to overcome the impact of lower incomes and educational levels, poorer sanitary conditions, and other factors that favor urbanites.
} 
health risks and problems, they may be less aware of and concerned about their own health than they should be (for example, if they have high blood pressure, elevated cholesterol, or an undetected tumor). In short, some combination of lower expectations and lower awareness of health problems may contribute to the higher scores of rural-origin respondents on self-rated physical health. ${ }^{45}$

However, these considerations don't apply so readily to the significantly lower regression coefficients of villagers and migrants on the emotional distress scale. It is not clear why different expectations and awareness should lead urbanites to be more predisposed than rural residents or migrants to feel or acknowledge worries about small things, having difficulty sleeping, or the other emotional distress signals we inquired about.

In addition to differing expectations and awareness, it is worth considering the role of past personal and family experiences in shaping current assessments of both physical and emotional health. During the Mao era, rural residents were subjected to a form of subordination and systematic discrimination that was tantamount to "socialist serfdom." They were forbidden to migrate elsewhere in search of better opportunities as Chinese villagers had done for centuries and also forbidden to undertake extensive handicraft, construction, marketing, or small business activities in order to improve their lot. Instead they were required to participate in collectivized agriculture (mainly growing grain) while being deprived of the many subsidies and welfare benefits, not to mention state investment largesse, enjoyed by urban residents. ${ }^{46}$ More rural than urban residents also have active memories of meager diets during the Mao era, consisting largely of cereals, with little meat or fish, fresh fruits, tofu, or peanuts, and active memories or family recollections as well of the mass famine deaths that racked the countryside 45 years

\footnotetext{
${ }^{45}$ One recent China survey employed a more complex and concrete 16 item index of self-reported physical health (covering mobility, pain and discomfort, vision problems, energy, and other domains) and also found in a regression analysis significantly lower health scores for urban respondents than rural ones, a finding the authors of the study attributed to differential expectations. See Ajay Tandon, Juzhong Zhuang, and Somnath Chatterji, "Inclusiveness of Economic Growth in the People's Republic of China: What Do Population Health Outcomes Tell Us?" Asian Development Review, 23 (2006): 53-69. Another survey found that saying that an older family member was currently ill or had been sick within the past four weeks was significantly more common for urban than for rural respondents. See Zimmer, "An Examination of Urban Versus Rural Mortality."

${ }^{46}$ As noted earlier, an abundant literature documents the systematic discrimination against rural areas and residents during China's socialist era. See the overview presented in Whyte, ed., One Country, Two Societies. In the Mao era strict controls over migration meant that the category of migrants essentially did not exist. In China today, in contrast, the number of migrants is variously estimated at anywhere from 130 to 200 million.
} 
prior to our survey, the product of Mao's failed Great Leap Forward campaign. State policy fostered a network of low quality health providers by the end of the Mao era, but thereby also put the health needs of villagers at the mercy of the questionable judgments of these local gate-keepers.

Given this historical context, the market reforms and other changes implemented in China after 1978 represent a form of "liberation" from socialist serfdom for those of rural origin. They now can partially or completely abandon farming in favor of rural factory work, commerce, construction, or other trades, and they can leave the village entirely to seek opportunities in the city, although as migrants they still remain second-class citizens compared to those with urban registrations. Their diet has improved considerably, as has their access to running water and improved sanitation facilities, as well as to urban hospitals, as noted earlier. Given the suppressed standard of living and persistent hunger of rural residents during the Mao era, in some sense they had nowhere to go but up as a result of market reforms. And in fact larger proportions of both rural residents (66.1\%) and migrants (76\%) reported that their families were doing better in 2004 than five years earlier, both figures surpassing the proportion of urban residents who reported improvement (59.1\%). ${ }^{47}$ In other words, even though a majority of respondents of all types reported improved standards of living and optimism about the future, rural residents and migrants were significantly more likely than urbanites to do so.

The less optimistic outlook of China's urbanites reflects the more complex consequences of market reforms in the cities. Although many urbanites have prospered during the reform era, and in fact the urban-rural gap in average incomes has widened in recent years, there is also a substantial minority of city dwellers who have lost out and continue to have their livelihoods threatened. In the socialist era the workings of employment and labor assignment institutions essentially eliminated unemployment, while urbanites benefited from the employment and benefit security that derived from the leadership's urban priorities. In the wake of the reforms, and particularly since the mid-1990s as a result of the drive launched by then-Premier Zhu Rongji to reform state enterprises by "smashing the iron rice bowl," substantial numbers of urban residents have lost jobs, had their firms go out of business, seen their

\footnotetext{
${ }^{47}$ This question was used as the first subjective status variable in Table 3.
} 
compensation and benefits slashed, or have suffered other setbacks leading to descent into poverty. ${ }^{48}$ Ways in which the post-1978 changes have posed increased threats to health in the form of rising obesity, increased air and water pollution, and new epidemic diseases (e.g. SARS, H1N1 flu) are also likely to more apparent to urban citizens than to their rural-origin counterparts. Urbanites are also particularly affected by the current excess demand and overcrowding of city hospitals.

These contrasting recent experiences help explain a common pattern found in other results from the 2004 survey--for respondents with rural origins to have more positive views of market reforms than their counterparts of urban origin, more acceptance of current patterns of inequality, and more optimism about getting ahead in the future. ${ }^{49}$ It seems likely that these contrasts in recent experiences are an additional influence that inclines rural residents and migrants to feel better than urbanites about their current physical health and to report fewer symptoms of emotional distress, despite their lower objective social and economic status. The influence of diverging personal experiences under socialism and since may also explain why, net of other factors, villagers are significantly less likely than urban citizens to be worried about paying future medical bills, while migrants are at least no more likely than the comparison group to have such worries (see columns 7-8 in Table 3), even though in terms of income and health insurance coverage, urbanites should have much less reason to worry.

We also noted a strong tendency for rural residents and migrants to be more accepting than urbanites of individual and family responsibility for health care, a difference likely rooted in the fact that under socialism the government mostly provided subsidies and benefits to urbanites while imposing restrictions and controls on the rural population. China's rural citizens, even though they remain on average poorer than their urban counterparts, are more confident of their ability to benefit from market reforms and less inclined to rely on state largesse, and we presume that this confidence carries over to some extent into their optimism about securing needed medical care and better health. In sum, lower

\footnotetext{
${ }^{48}$ See Azizur Khan and Carl Riskin, Inequality and Poverty in China in the Age of Globalization. (New York: Oxford University Press, 2001).

${ }^{49}$ These findings are summarized in Whyte, Myth of the Social Volcano. See also Chunping Han, Rural-Urban Cleavages in Perceptions of Inequality in Contemporary China, unpublished doctoral dissertation, Department of Sociology, Harvard University, 2009.
} 
expectations and less awareness of health problems may partially explain the second puzzle of why more Chinese of rural origins than urbanites rate themselves healthy physically and emotionally. However, contrasts in the nature of life under socialism in the past and the differential consequences of market reforms likely also play a powerful role in explaining why on average rural residents and migrants rate their current physical and emotional health so positively.

\section{Conclusions}

China's post-1978 market reforms dismantled key features (such as near-universal basic medical insurance coverage) of what had been quite a successful health care system. Numerous critical voices have been raised since, within China and outside, condemning the altered health care system as not promoting or even as undermining the health status of the population.

One recent analysis portrays the Chinese health care system as in crisis, with potentially dire consequences:

Gaps in health care are an important reason for growing anger in some rural districts toward the Chinese government, the Chinese Communist Party, and China's new, wealthy elite and are contributing to increasingly frequent local riots and disturbances in rural China. In a country where threats to established political authority (such as the communist revolution itself) have sprung up for millennia from the grievances of an impoverished peasantry, the consequences of differentials between rural and urban health care carry profound political significance for the Chinese leadership. ${ }^{50}$

Although the Chinese health care system early in the new millennium faced (and will continue to face) very serious challenges and problems, our analyses suggest that such statements are excessively apocalyptic. Despite the threats to citizen health represented by the sharp reductions in medical insurance coverage, rising costs of medical care, and unequal access, China nonetheless has made dramatic progress in improving the health of its population in the three decades since market reforms were launched. ${ }^{51}$ By

\footnotetext{
${ }^{50}$ Blumenthal and Hsiao, "Privatization and its Discontents," p. 1168.

${ }^{51}$ Some analysts contend that even if China's market reforms did not reverse the Mao-era trend of improved life expectancy, they resulted in much slower improvement. See, for example, Amartya Sen, "Life and Death in China: A Reply," World Development, 9 (1992): 1305-12; Shaogang Wang, "China's Health System: From Crisis to
} 
almost any indicator the average Chinese is healthier today than at the end of the Mao era. The deterioration in life expectancy and other health indicators that occurred in Russia and many countries in Eastern Europe was avoided in China.

Furthermore, this improvement in average health was not driven primarily by improvements in the health of the wealthy and successful. To a considerable extent the improvements in health since 1978 have been broadly shared. To be sure, considerable gaps remain between the health status of China's urban and rural citizens, the wealthy and the poor, and residents of rich coastal provinces and poor inland locales. It turns out that China is not, after all, an exception to the worldwide pattern of advantaged citizens having better health than their less fortunate countrymen. Objective health indicator data from prior research show, in particular, that the average Chinese urban citizen is healthier than the average villager or urban migrant. ${ }^{52}$ However, despite ominous warnings and claims to the contrary, the gains in the health of urban citizens have not come at the expense of their rural-origin fellow citizens, and by some measures (such as infant and maternal mortality rates) the urban-rural health gap has actually declined in recent years. ${ }^{53}$

Furthermore, the survey evidence in the latter part of this paper doesn't suggest growing anger in rural areas regarding health inequalities. As of 2004, at least, Chinese of rural origin, both villagers and urban migrants, had more positive views of their own health and about their ability to deal with medical costs than we would expect, and in many respects more positive views than their urban fellow citizens. ${ }^{54}$ While the reasons for this surprising optimism are no doubt complex, we suggest that not only differing

Opportunity," Yale-China Health Journal, 3 (2004): 5-49. However, an increase of roughly 14 years in life expectancy at birth over 30 years, between the mid-1970s and 2005 (see Banister's estimates in fn. 8), and the convergence with the rates of much richer countries such as Poland and Hungary shown in Figure 1, is a substantial accomplishment. Furthermore, in any society the rate of improvement in life expectancy slows once the leading causes of mortality become chronic rather than infectious diseases. See the discussion in Banister and Hill, "Mortality in China 1964-2000."

${ }^{52}$ See Yip, "Disparities in Health Care and Health Status;" Zhao, "Income Inequality, Unequal Health Care Access, and Mortality in China;" Zimmer et al., "An Examination of Rural Versus Urban Mortality in China." Even for life expectancy at birth, where the urban-rural gap increased between 1990 and 2000 (from 3.5 to 5.5 years), the rural indicator has continued to improve-from 67 years in 1982 to 69.2 years in 1990 and 70.6 years in 2000 (estimates courtesy of Cai Yong).

${ }_{54}^{53}$ See the figures cited in Yip, "Disparities in Health Care and Health Status."

${ }^{54}$ Whyte is directing a follow-up national survey in China on these same issues in 2009, and the data from the new survey will be used to examine changes in attitudes toward health care and other issues since 2004. 
expectations and awareness, but also a subjective sense of greater improvements on average (compared to urbanites) in the lives and mobility opportunities of Chinese rural citizens spills over and fuels positive outlooks about their current health and their ability to deal with medical problems and expenses. As a result, and despite their many objective disadvantages compared to urbanites, Chinese of rural origins are less critical and more positive about their health than we might expect.

Our challenge here to critiques of the Chinese health system is not meant as a call for complacency. Since 2003 China has mounted a multi-pronged effort to increase funding for health care, provide broader medical insurance coverage, remove barriers to health care access, and thus reduce inequalities in health care access and health status, particularly between rural and urban citizens. We view these new initiatives as a long overdue effort to correct the problems the post-1978 reforms created in the health care system. In China it is still too common, unfortunately, for individuals to forego medical treatment because they can't afford the expense, to leave an expensive hospital before they should and to die at home, or to be bankrupted by huge bills assessed for needed surgery of a family member. China's poor and disadvantaged (villagers and migrants included) are the ones most affected by these problems.

However, the evidence reviewed here suggests that both objective health indicators and the patterning of popular attitudes provide a more positive context for attacking health problems than much of the existing literature suggests. Despite the common complaint that seeking medical treatment is difficult and expensive, this more positive context includes considerable confidence and optimism among Chinese citizens, and particularly among those of rural origins, about their health. These sentiments are driven mainly by the extraordinary economic development success China has experienced since 1978, a trend that produced major improvements in citizen health despite serious flaws in China's health care system. These sentiments may provide "breathing room" that will enable the new post-2003 health care initiatives time to take effect. If China's economic development pace can be sustained, particularly in ways that create improved opportunities for villagers and other disadvantaged groups, and if a comprehensive and effective network of medical care institutions can be created as a result of the post-2003 initiatives, then China's progress in improving the health of its 1.3 billion citizens will no longer appear so puzzling. 